\title{
The routine determination of manganese with formaldoxime
}

\section{J. CH. VAN SCHOUWENBURG}

State Agricultural University, Laboratory of Soils and Fertilizers, Wageningen, and Institute for Soil Fertility, Groningen, Netherlands

\section{Summary}

The interference of iron when manganese is determined using formaldoxime can be succesfully masked with $\mathrm{KCN}$ in combination with measuring at a wavelength of $500 \mathrm{~mm}$.

\section{Introduction}

The determination of $\mathrm{Mn}$ with formaldoxime is influenced by $\mathrm{Fe}, \mathrm{Cu}, \mathrm{Ni}, \mathrm{Co}, \mathrm{Ce}$ and V (MARCZENKo, 1964). In plant material or soil extracts the latter three elements do not occur to an extent that might cause serious interference. $\mathrm{Cu}, \mathrm{Ni}$ and $\mathrm{Co}$ can readily be masked with $\mathrm{KCN}$. However, in the alkaline medium necessary for the development of the Mn-formaldoxime colour, $\mathrm{KCN}$ and every other masking agent tested by this author, produces a yellow-brown colour with $\mathrm{Fe}$, probably due to the formation of $\mathrm{FeOH}$ complexes. These coloured complexes, if present at rather high levels, will in their turn interfere with the determination of $\mathrm{Mn}$.

\section{Experimental}

VAN DEN HeNde and CotTenie (1960) describe a method using KCN as a masking agent. In this method formaldoxime is added last, which is rather an attractive feature because in doing so the autooxidation of the reagent is prevented to a large extent, provided the formaldoxime is mixed immediately with the sample to which the other reagents already have been added.

A scaled-down modification of this method was used to study the interference of iron. To solutions containing $25 \gamma$ of $\mathrm{Mn}$ were added $0,250,500$ or $1000 \gamma$ of Fe. Next, the formaldoxime-Mn colour was developed, the final volume being $25 \mathrm{ml}$. Spectrograms of the resulting solutions were made. These are presented in FIG. 1.

The spectrograms proved that the influence of iron could be minimized if measurements were made at $500 \mathrm{~nm}$. instead of the $450 \mathrm{~nm}$. normally used.

For the quantitative determination of the interference of iron measurements were made at 450, 500, 520 and $530 \mathrm{~nm}$. For this purpose increasing quantities of $\mathrm{Fe}$ were added to solutions containing $20 \mathrm{\gamma}$ of $\mathrm{Mn}$; the Mn-formaldoxime colour was developed and the final volume made up to $25 \mathrm{ml}$. The results are presented in the TABLE and in FIG. 2.

Received for publication 19th August, 1965 ; 


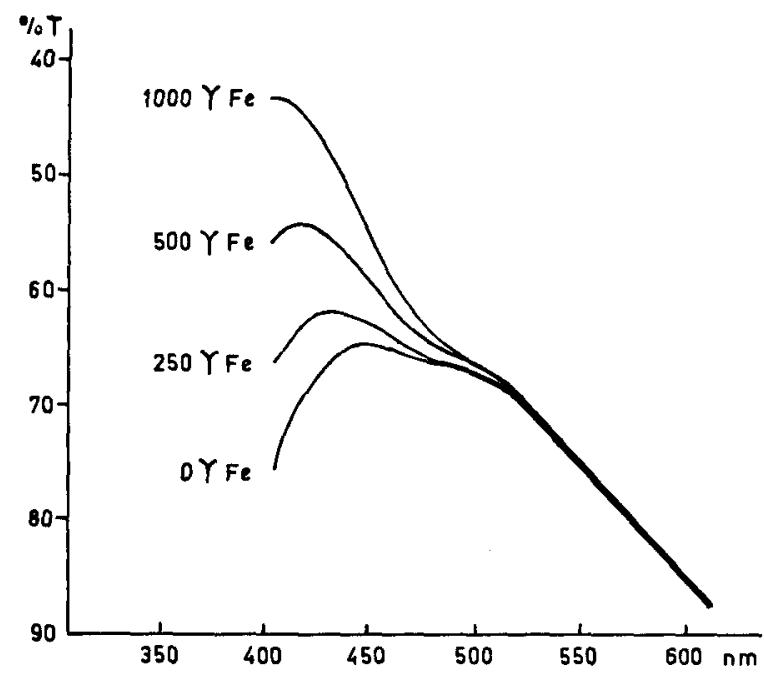

Fig. 1

The influence of increasing quantities of iron on the determination of $\mathrm{Mn}$ with formaldoxime

\section{Discussion}

The iron salt originally used for the experiments, $\mathrm{FeSO}_{4}\left(\mathrm{NH}_{4}\right)_{2} \mathrm{SO}_{4} .6$ aq, contained some $\mathrm{Mn}$ as a contaminant. The $\mathrm{Fe}$,was therefore extracted from a $6 \mathrm{n} \mathrm{HCl}$ medium with ether and back-extracted into $1.2 \mathrm{n} \mathrm{HCl}$.

The results as presented in the TABLE and in FIG. 2 suggest a linear relationship between extinction values and amounts of $\mathrm{Fe}$ present.

Furthermore, measurement at a wavelength of $500 \mathrm{~nm}$. resulted in very small interference if $\mathrm{Fe}$ with only $9 \%$ loss in sensitivity.

If measured at $500 \mathrm{~nm}$. a $\mathrm{Fe} / \mathrm{Mn}$ ratio of 50 will result in a positive error of about $0.010-0.013$ extinction units corresponding with an average relative error of about $8.4 \%$.

In soil and plant analysis such ratios are, according to the author's experience, not to be expected. The $\mathrm{Fe} / \mathrm{Mn}$ ratio will probably never exceed a value of 20 ; normally this ratio will be less than 10 . Because of the linear character of the interference of $\mathrm{Fe}$, the errors produced with this simplified procedure will probably not exceed

TABLE. Extinction values of solutions containing $20 \gamma$ of $\mathrm{Mn}$ together with increasing quantities of $\mathrm{Fe}$, measured at different wavelengths

\begin{tabular}{cccccc}
\hline $\begin{array}{c}\gamma \text { of } \mathrm{Mn} \\
\text { added }\end{array}$ & $\begin{array}{c}\gamma \text { of Fe } \\
\text { added }\end{array}$ & 450 & 500 & \multicolumn{3}{c}{ Extinction values $(\times 1000)$ at } \\
\hline & 0 & 151 & 137 & 126 & $530 \mathrm{nnm}$ \\
20 & 250 & 170 & 140 & 129 & 117 \\
20 & 500 & 187 & 144 & 131 & 120 \\
20 & 750 & 203 & 145 & 133 & 123 \\
20 & 1000 & 219 & 147 & 134 & 124 \\
20 & 1000 & 71 & 13 & 10 & 9 \\
0 & & & & & \\
\hline
\end{tabular}

Blank values have been subtracted. 
$4 \%$ and in normal cases be of the order of $2 \%$ or even less. According to FERrari and VERMEULEN (1955), the variation coefficient of a soil sample will be about $10 \%$ in the case of $\mathrm{P}, \mathrm{K}$ and $\mathrm{Mg}$. There is no reason to believe that plant samples will show a smaller variation coefficient with these and, probably, other elements. This means that the overall-variation coefficient even in extreme cases, will only increase from $10 \%$ to $10.8 \%$ at a $\mathrm{Fe} / \mathrm{Mn}$ ratio of 20 . If considered necessary, which however seems unpractical, it is possible to correct for the $\mathrm{Fe} / \mathrm{Mn}$ ratio because the $\mathrm{Fe}$ interference proved to be reproducible with the method described.

The measurements were made with an Optica CF4 spectrophotometer. For routine determinations at $500 \mathrm{~nm}$., a colorimeter with interference filters (for instance a Vitatron with 505 filter) can be used as well.

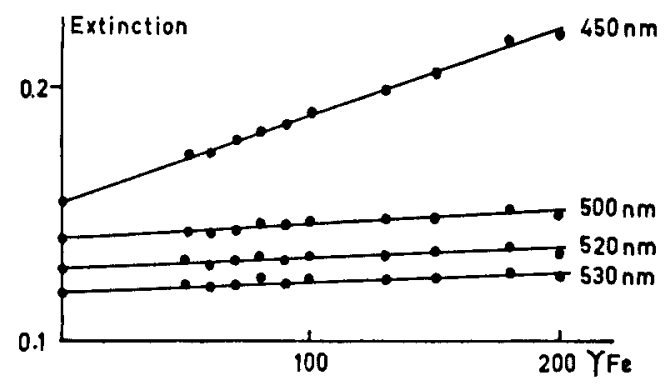

FIG. 2

The influence of the wavelength on the interference of $\mathrm{Fe}$

\section{Reagents}

Only analytical grade chemicals have been used.

a. metol-sulphite solution: dissolve $0.1 \mathrm{~g}$ of metol (p-methylaminophenol sulphate), $13.7 \mathrm{~g}$ of $\mathrm{Na}_{2} \mathrm{~S}_{2} \mathrm{O}_{5}$ and $1 \mathrm{~g}$ of $\mathrm{Na}_{2} \mathrm{SO}_{3} .7$ aq and make up to $100 \mathrm{ml}$. This solution will keep for at least 1 month.

b. alkaline $\mathrm{KCN}$ solution: $\operatorname{mix} 20 \mathrm{ml}$ of $\mathrm{KCN} 10 \%, 100 \mathrm{ml}$ of $\mathrm{NH}_{4} \mathrm{OH}$ (s.w. 0.910) and $360 \mathrm{ml}$ of distilled water.

c. formaldoxime reagent: dissolve $5 \mathrm{~g}$ of hydroxylamine- $\mathrm{HCl}$ in a mixture of $5 \mathrm{~g}$ of formaldehyde $40 \%$ and about $80 \mathrm{ml}$ of distilled water. Make up to $100 \mathrm{ml}$. This solution will keep for at least 1 month. The procedure of vaN DEN HENDE and Cortenie is followed here although most authors use less formaldehyde for the preparation of the reagent.

d. standard solution of $10 \mathrm{ppm} \mathrm{Mn}$ : dissolve in a $600-\mathrm{ml}$ beaker $0.288 \mathrm{~g}$ of $\mathrm{KMnO}_{4}$ in about $200 \mathrm{ml}$ of distilled water to which has been added $45 \mathrm{ml}$ of $\mathrm{H}_{2} \mathrm{SO}_{4}$ (s.w. 1.84). Reduce the $\mathrm{KMnO}_{4}$ with a few drops of $\mathrm{H}_{2} \mathrm{O}_{2} 30 \%$. Boil to expel the excess of $\mathrm{H}_{2} \mathrm{O}_{2}$. Rinse the cooled solution into a 1-litre volumetric flask and make up to volume. Pipette $100 \mathrm{ml}$ of this solution into a 1-litre volumetric flask and make up to volume.

\section{Procedure}

The procedure is in fact a scaled-down modification of the procedure of VAN DEN Hende and Cottenie.

Pipette into test tubes $2 \mathrm{ml}$ of the sample solution and add $0.5 \mathrm{ml}$ of the metol- 
sulphite- and $2.4 \mathrm{ml}$ of the alkaline $\mathrm{KCN}$ solution. Mix and wait 15 minutes. Then add 2 drops of the formaldoxime reagent. Mix immediately. Wait 30 minutes before measuring at $500 \mathrm{~nm}$. in a $1-\mathrm{cm}$ cuvette.

The procedure described can also be used with a Morgan's soil extract. For the analysis of plant material it can be applied to all media that, by their acidic nature, do not cause the final $\mathrm{pH}$ to drop below a value of 10 .

No interferences were found with $100 \gamma$ quantities of either $\mathrm{Co}, \mathrm{Cu}, \mathrm{Ni}$ or $\mathrm{Zn}$. Larger quantities have not been tested.

Ferrari, Th. J., and F. H. B. Vermeulen

HENDE, A. VAN DEN, and A. H. CotTenie

MarczenKo, $Z$.

\section{REFERENCES}

1955 Soil heterogeneity and soil testing. Neth. J. agric. Sci. 3, $265-275$.

1960 L'estimation de la fertilité du sol par les méthodes chimiques nouvelles. Travaux du Centre de Chimie Physique Agricole. No. 25. I.R.S.I.A., Bruxelles.

1964 Dosage spectrophotométrique de différents métaux (Mn, Ce, $\mathrm{V}, \mathrm{Ni}, \mathrm{Fe}$ ) au moyen de la formaldoxime. Anal. Chim. Acta. $31,224-232$. 